ОСОБЛИВОСТІ ЦИРКАДНОГО РИТМУ АРТЕРІАЛЬНОГО ТИСКУ ПАЦІЕНТІВ 3 РЕЗИСТЕНТНОЮ АРТЕРІАЛЬНОЮ ГІПЕРТЕНЗІЕЮ ТА ПСЕВДОРЕЗИСТЕНТНОЮ АРТЕРІАЛЬНОЮ ГІПЕРТЕНЗІЕЮ

\title{
М.Ю. Шеремет
}

ДУ «Національний науковий центр “Інститут кардіології імені академіка М.Д. Стражеска” НАМН України», м. Київ

\section{Ключові слова: резистентна артеріальна гіпертензія, ичиркадний ритм артеріального тиску.}

Буковинський медичний вісник. T.22, № 3 (87). C. 117-123.

\section{DOI:}

10.24061/2413-0737. XXII.3.87.2018.74

E-mail:mjset@hotmail. com
Мета роботи - визначити особливості ичиркадного ритму артеріального тиску в пацієнтів з істинною резистентною артеріальною гіпертензією (РАГ) та псевдорезистентною артеріальною гіпертензією (ПРАГ).

Матеріал і методи. Обстежено 52 пацієнти з підозрою на (РАГ) згідно з критеріями Свропейського товариства гіпертензї (ЕSH, 2013). 44 паиієнтам з підозрою на РАГ було призначено антигіпертензивну терапію (інгібітор АПФ/сартани, антагоніст кальцію та діуретик) у максимальних терапевтичних дозах. Через два місяці лікування у 20 паичієнтів на тлі комбінованої терапї досягти нормалізації артеріального тиску (АТ) не вдалось, щчо підтвердило наявність РАГ. Ці пацієнти склали I групу. Натомість у 24 обстежених АТ нормалізувався, щзо свідчило про псевдорезистентний перебіг АГ. Ці пачієєти склали групу контролю (ІІ група). Всім пацієнтам виконували вимірювання офісного та амбулаторного АТ для оцінки характеристик изиркадного ритму АT. Результати. За даними добового моніторування артеріального тиску (ДМАТ) у пацієнтів з РАГ реєструвався значно більший рівень систолічного АТ (САТ) протягом доби, дня та ночі, а також показник середнього діастолічного АТ (ДАТ) вночі. Добові індекси за САТ і ДАТ були значно нижчими в групі пацієнтів із РАГ. Недостатнє зниження нічного AT (mun «non-dipper») спостерігали у 8 (35\%) хворих; «nighpiker» - y 5 пацієнтів (25\%). Решта пацуієнтів мали нормальний профіль цчиркадного ритму АТ. У II групі 11 (45,8\%) пацієнтів мали нормальний добовий профіль $A T$, у $8(33,4 \%)$ пацієнтів виявлено його порушення за типом «nоn-dipper», лише у двох пацієнтів спостерігали тип «nighpiker» (8,3\%), та в трьох пацієнтів (12,5\%) - зафіксували надмірне зниження АТ у нічний період — тип “over-dipper".

Порушення варіабельності АТ значно частіше виявляли в I групі (72,7\%), ніж у II групі - 43,0\% (p=0,04). Ранкові прирости САТ і ДАТ теж були достовірно вищими у хворих I групи ( $p=0,026$ і $p=0,001$ відповідно).

Висновки. Пацієнти з резистентною артеріальною гіпертензією характеризуються більш високими показниками систолічного артеріального тиску за даними добового моніторування артеріального тиску в денний та нічний період; мають частіше порушення циркадного ритму за типом «non-dipper», «night-piker» та значно вищчими показниками ранкового приросту артеріального тиску порівняно з псевдорезистентним перебігом артеріальної гіпертензіі.

\author{
ОСОБЕННОСТИ ЦИРКАДНОГО РИТМА \\ АРТЕРИАЛЬНОГО ДАВЛЕНИЯ У ПАЦИЕНТОВ С \\ РЕЗИСТЕНТНОЙ АРТЕРИАЛЬНОЙ ГИПЕРТЕНЗИЕЙ И \\ ПСЕВДОРЕЗИСТЕНТНОЙ АРТЕРИАЛЬНОЙ ГИПЕРТЕНЗИЕЙ \\ М.Ю. Шеремет
}

\section{Ключевые слова: \\ резистентная \\ артериальная \\ гипертензия, \\ ициркадный ритм}


Оригінальні дослідження

артериального

давления.

Буковинский медициинский вестник. T.22, № 3 (87). С. 117-123.
Keywords: resistant arterial hypertension, circadian rhythm of blood pressure.

Bukovinian Medical Herald. V.22, № 3 (87). P. 117-123.
Цель работы - изучить особенности цииркадного ритма артериального давления у паџиентов с истинной резистентной артериальной гипертензией (РАГ) и псевдорезистентной артериальной гипертензией (ПРАГ). Материал и методы. Обследовано 52 пациента с подозрением на резистентную артериальную гипертензию (РАГ) согласно критериев Европейского общества гипертензии (ЕSH, 2013). 44 пациентам с подозрением на РАГ было назначено антигипертензивную терапию (ингибитор АПФ/сартаны, антагонист кальция и диуретик) в максимальных терапевтических дозах. Через два месяиа лечения у 20 пацчентов на фоне комбинированной терапии достичь нормализации артериального давления (АД) не удалось, что подтвердило наличие РАГ (I группа). Тогда как у 24 обследованных артериальное давление нормализовалось, что свидетельствует о псевдорезистентном течении АГ (II группа). Всем пациентам выполняли измерения офисного и амбулаторного АД для оценки характеристик ичиркадного ритма АД в группах наблюдения. Результаты. По данным суточного мониторирования артериального давления (СМАД) у пациентов с РАГ регистрировался значительно больиий уровень САД в течении суток, дня и ночи, а также показатели средненочного уровня диастолического артериального давления (ДАД). Суточные индексы САД и ДАД были значительно ниже в группе пациентов с РАГ. Недостаточное снижение ночного АД (mun «non-dipper») наблюдалось у 8 (35\%) пациентов; «night-piker» - у 5 (25\%) пациентов, когда ночное АД значительно выше за дневное АД. Остальные пациенты имели нормальный профиль ичиркадного ритма АД. Во ІІ группе $8(33,4 \%)$ пациентов имели нарушение по типу «nоn-dipper», у двоих (8,3\%) пациентов наблюдали тип «night-piker», и у mpоuх (12,5\%) naцчиентов - зафиксировали чрезмерное снижение АД в ночной период - mun «over-dipper».

Нарушение вариабельности АД значительно чаще выявляли в I группе (72,7\%), чем во II группе - 43,3\% (p=0,04). Утренние приросты САД и ДАД также были достоверно выше у больных I группь ( $p=0,026 u$ p=0,001 соответственно).

Вывод. Пациенты с резистентной артериальной гипертензией характеризуются более высокими показателями систолического артериального давления по данным суточного мониторирования артериального давления в дневной и ночной периоды; чаще имеют нарушения цииркадного ритма по muny «non-dipper», «night-piker» и значительно выше показатели утреннего прироста артериального давления по сравнению с псевдорезистентним течением артериальной гипертензии.

\section{FEATURES OF A CIRCADIAN RHYTHM OF ARTERIAL PRESSURE IN PATIENTS WITH RESISTANT ARTERIAL HYPERTENSION AND PSEUDO-RESISTANT ARTERIAL HYPERTENSION}

M.Yu. Sheremet

Aim: To determine the peculiarities of circadian rhythm of arterial pressure in patients with true resistant arterial hypertension $(R A H)$ and pseudo-resistant arterial hypertension (PRAH).

Material and methods. 52 patients with suspected resistant arterial hypertension (RAH) were examined according to the criteria of the European Society of Hypertension (ESH, 2013). Antihypertensive therapy (ACE inhibitors/sartans, calcium antagonist, and a diuretic) was administered to 44 patients 
with suspected RAH in the maximum therapeutic doses. In 20 patients, with the combined therapy, the normalization of blood pressure was not achieved. The presence of RAH confirmed it. These patients formed group I. However, blood pressure in 24 examined patients was normalized, indicating a pseudo-reflective course of hypertension. These patients formed a control group (group II). The measurements of the office and ambulatory blood pressure were performed in all patients for assessing the characteristics of a circadian rhythm of blood pressure.

Results. According to ambulatory blood pressure monitoring (ABPM), in patients with RAH, a significantly higher level of systolic blood pressure $(S B P)$ was recorded daily, during daytime and nighttime, as well as mean night value of diastolic blood pressure (DBP). The daily indices of SBP and $D N P$ were significantly lower in the group of patients with RBP. Insufficient reduction of blood pressure (type "non-dipper") was observed in 8 (35\%) patients in nighttime; "Nigh-piker" - in 5 patients (25\%). The rest of the patients had a normal circadian rhythm profile of BP. In group II, 11 (45.8\%) patients had normal daily blood transfusion profile, $8(33.4 \%)$ patients had non-dipper disorders, only 2 patients had nigh-piker type (8, 3\%), and in three patients $(12.5 \%)$ - recorded excessive decrease in blood pressure at night over-dipper type. The disturbance of the variability of blood pressure were found more frequently in group I (72.7\%) than in the II group - 43.0\% (p $<0.04$ ). The morning gains of SBP and DBP were also significantly higher in patients of the group I ( $p=0,026$ and $p=0,001$, respectively).

Conclusion. Patients with RBP are characterized by higher SBP data according to BPMM during the daytime and nighttime. They have more frequent disturbances of the circadian rhythm due to type of "non-dipper", "night-piker" and significantly higher values of morning BP increase compared with the pseudo-resistant arterial hypertension.

Вступ. Актуальність. Поширеність резистентної артеріальної гіпертензії (РАГ) вивчена недостатньо порівняно з контрольованою артеріальною гіпертензією. За даними реєстру NHANES (США) серед пацієнтів з артеріальною гіпертензією (АГ) поширеність РАГ постійно збільшується протягом останніх 30 років і в середньому становить $8,9 \%$ [1]. Статистика Франції, Німеччини, Великобританії та Іспанії демонструє більш поширену РАГ до лікування — від 14,6\% до $17,5 \%$ [2]. Серед дорослого населення України близько 33\% мають підвищений рівень артеріального тиску (АТ). У 5-30\% з них, за різними даними, спостерігається резистентний перебіг АГ [3].

Добовий моніторинг АТ є невід'ємною складовою в процесі діагностики РАГ, оскільки надає змогу виключати пацієнтів з “гіпертензією білого халату". Крім цього, даний метод $\epsilon$ цінним для оцінки ризику розвитку кардіоваскулярних ускладнень та визначення несприятливого перебігу АГ. Важливим фактом $€$ те, що за даними чисельних досліджень амбулаторний АТ порівняно з офісним, більш тісно корелює 3 ураженням органів - мішеней і відіграє провідну роль в оцінці ефективності підібраної антигіпертензивної терапії. Особливу роль відіграють показники циркадного ритму АТ, що $є$ незалежним фактором пошкодження органів-мішеней [4]. У пацієнтів з РАГ виникнення інфаркту міокарда, інсульту, хвороби нирок, та смертність, як кінцева точка, у 2-6 разів вищий порівняно з контрольованою АГ [5].

Суттєвий вплив на прогноз пацієнтів з АГ справляє наявність і характер ураження органів-мішеней. Тому важливим завданням лікування $\epsilon$ не лише досягнення цільових рівнів АТ, але й своєчасне виявлення ураження органів-мішеней, оскільки це може уповільнити прогресування процесу, знизити ризик розвитку серцево-судинних подій, інвалідизації та смертності пацієнтів [6].

Мета роботи - визначити особливості циркадного ритму АТ у пацієнтів із РАГ та ПРАГ.

\section{Матеріал і методи.}

У дослідження було включено 52 пацієнти з підозрою на РАГ. АГ вважається резистентною (за визначенням Європейського товариства гіпертензії, ESH, 2013), якщо на фоні модифікації способу життя, при прийомі трьох або більше антигіпертензивних препаратів, включаючи діуретик, не досягнуто цільового рівня АТ ( $<140 / 90$ мм рт.ст.). У скринінг не включали пацієнтів, які були неспроможні або не бажали підписати інформованої згоди, мали тяжкі порушення серцевого ритму, що потребували лікування, серце- 
во-судинні ускладнення (інфаркт міокарда, мозковий інсульт - протягом 6 місяців до включення в скринінг) та онкозахворювання. Всім пацієнтам проведено комплексне клінічне обстеження з урахуванням скарг, анамнестичних та об'єктивних даних: фізикальне обстеження, вимірювання офісного АТ та частоти серцевих скорочень (ЧСС), зросту, ваги, окружності талії (ОТ).

На початку дослідження всім пацієнтам виключали вторинний генез АГ (первинний альдостеронізм, феохромоцитому, стеноз ниркових артерій та ін.). Для цього, зокрема, визначали рівень активного реніну, альдостерону та їх співвідношення в плазмі крові, рівень добової екскреції метанефринів із сечею, проводили комп'ютерну томографію (КТ) нирок та надниркових залоз із в/в контрастуванням ниркових артерій. Первинний альдостеронізм було виявлено у 8 пацієнтів, які не включені в представлений аналіз. 44 пацієнтам з підозрою на РАГ було призначено антигіпертензивну терапію (інгібітор АПФ/сартани, антагоніст кальцію та діуретик) у максимальних те- рапевтичних дозах. У 20 пацієнтів на тлі комбінованої терапії досягти нормалізації АТ не вдалось, що підтвердило наявність РАГ. Ці пацієнти склали I групу. Псевдорезистентним вважали перебіг АГ за умови досягнення цільового рівня АТ за даними ДМАТ (<135/85 мм рт.ст.) на фоні 2-місячного прийому трикомпонентної антигіпертензивної терапії, включаючи діуретик, з використанням за необхідності максимально переносимих доз препаратів. Через два місяці лікування АТ нормалізувався у 24 обстежених, що свідчило про псевдорезистентний перебіг АГ (ПРАГ). Ці пацієнти склали групу контролю (II група).

У пацієнтів із РАГ тривалість перебігу захворювання склала в середньому $(16,3 \pm 2,3)$ роки, у групі ПРАГ — $(13,4 \pm 2,0)$ роки. У групі з РАГ у 16 пацієнтів діагностовано гіпертонічну хворобу II стадії та у 4 осіб - гіпертонічну хворобу III стадії, що зумовлено наявністю в анамнезі ускладнень АГ — порушення мозкового кровообігу (3 пацієнти) та транзиторної ішемічної атаки (1 пацієнт) понад 6 місяців. Серед всіх обстежених у 7 пацієнтів виявлено цукровий діабет,

Характеристика хворих з резистентною та псевдорезистентною артеріальною

Таблиця гіпертензісю

\begin{tabular}{|c|c|c|c|}
\hline Показник & Група з РАГ (n=20) & $\begin{array}{c}\text { Група з ПРАГ } \\
(\mathrm{n}=24)\end{array}$ & $\mathrm{p}$ \\
\hline 1 & 2 & 3 & 4 \\
\hline $\begin{array}{l}\text { Стать: } \\
\text { чоловіки } \\
\text { жінки } \\
\end{array}$ & $\begin{array}{c}8 \\
12 \\
\end{array}$ & $\begin{array}{c}15 \\
9 \\
\end{array}$ & \\
\hline Вік, роки & $51,4 \pm 2,6$ & $54,2 \pm 1,9$ & 0,63 \\
\hline 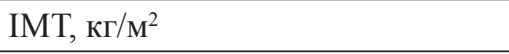 & $32,2 \pm 0,9$ & $33,4 \pm 1,1$ & 0,35 \\
\hline Офісний САТ, мм рт.ст. & $174,4 \pm 4,1$ & $175,5 \pm 4,5$ & 0,78 \\
\hline Офісний ДАТ, мм рт.ст. & $97,3 \pm 4,4$ & $102,4 \pm 2,4$ & 0,22 \\
\hline Середньодобовий САТ, мм рт. ст. & $169,2 \pm 2,8$ & $159,0 \pm 2,8$ & 0,03 \\
\hline Середньодобовий ДАТ, мм рт. ст. & $96,2 \pm 3,3$ & $89,5 \pm 2,3$ & 0,27 \\
\hline Середньоденний САТ, мм рт. ст. & $173,5 \pm 2,9$ & $164,6 \pm 2,4$ & 0,04 \\
\hline Середньоденний ДАТ, мм рт. ст. & $100,4 \pm 3,5$ & $94,0 \pm 2,4$ & 0,24 \\
\hline Середньонічний САТ, мм рт. ст. & $161,9 \pm 3,4$ & $148,6 \pm 4,2$ & 0,02 \\
\hline Середньонічний ДАТ, мм рт. ст. & $88,5 \pm 3,2$ & $80,6 \pm 2,4$ & 0,19 \\
\hline Добовий індекс САТ, \% & $6,7 \pm 1,2$ & $10,1 \pm 1,4$ & 0,02 \\
\hline Добовий індекс ДАТ, \% & $11,6 \pm 1,1$ & $15,0 \pm 1,3$ & 0,02 \\
\hline $\begin{array}{l}\text { Варіабельність САТ день, } \\
\text { мм рт.ст. }\end{array}$ & $16,9 \pm 1,0$ & $17,0 \pm 0,7$ & 0,79 \\
\hline $\begin{array}{l}\text { Варіабельність САТ ніч, } \\
\text { мм рт.ст. }\end{array}$ & $14,9 \pm 1,1$ & $14,1 \pm 0,7$ & 0,27 \\
\hline $\begin{array}{l}\text { Варіабельність ДАТ день, } \\
\text { мм рт.ст. }\end{array}$ & $11,7 \pm 0,7$ & $12,6 \pm 0,6$ & 0,27 \\
\hline $\begin{array}{l}\text { Варіабельність ДАТ ніч, } \\
\text { мм рт.ст. }\end{array}$ & $9,9 \pm 0,7$ & $10,6 \pm 0,4$ & 0,64 \\
\hline Ранковий приріст САТ, мм рт.ст. & $51,9 \pm 2,6$ & $40,6 \pm 4,2$ & 0,02 \\
\hline Ранковий приріст ДАТ, мм рт.ст. & $41,9 \pm 2,4$ & $30,1 \pm 2,4$ & 0,001 \\
\hline
\end{tabular}


3 них у 6 із РАГ та в одного - із групи контролю.

Обстеження проводили згідно 3 наказом МО3 України № 384 від 24.05.2012 р "Про затвердження та впровадження медико-технологічних документів зі стандартизації медичної допомоги при артеріальній гіпертензії" та рекомендацій Європейського товариства з артеріальної гіпертензії, Свропейської асоціації кардіологів 2013 року.

Вимірювання офісного АТ проводили згідно 3 правилами вимірювання за допомогою автоматичного приладу OMRON 705 IT, Японія.

3 метою виключення «гіпертензії білого халата», прихованої гіпертензії та для оцінки характеристик циркадного ритму АТ у групах спостереження застосовували метод добового моніторування артеріального тиску (ДМАТ), яке виконували на апараті АВРМ-04 (“Meditech", Угорщина) за загальноприйнятими методиками з визначенням наступних показників: середньодобового, середньоденного, середньонічного систолічного АТ (САТ) та діастолічного АТ (ДАТ), середньої ЧСС. Також визначали добовий індекс (ДІ), варіабельність (СВ) та ранковий приріст (РП) САТ та ДАТ. Вимірювання проводилися в автоматичному режимі з інтервалом кожні 15 хв у денний період (3 06.00 до 22.00 год), та кожні 30 хв у нічний період (3 22.00 до 06.00 год). Ранковий приріст АТ розраховували за формулою (окремо для САТ і ДАТ):

РП = АТ Макс. - АТ мін.,

де АТ Макс. - максимальний рівень АТ у період 3 04.00 до 10.00 год ранку (для САТ чи ДАТ), АТ мін.мінімальний рівень АТ у період з 04.00 до 10.00 год ранку (для САТ чи ДАТ).

Статистичну обробку отриманих результатів проводили за допомогою програмного забезпечення IBM Statistics SPSS 20 з визначенням середніх арифметич- них показників, стандартного відхилення від середньої арифметичної величини за рівномірним розподілом вибірки. Показники відображені у вигляді середньої та стандартної похибки середнього $(\mathrm{M} \pm \mathrm{m})$. Достовірною різницею вважали при $\mathrm{p}<0,05$.

Результати дослідження та їх обговорення.

Пацієнти обох груп не відрізнялись за віком, тривалістю АГ, індексом маси тіла (IMT) та значеннями офісного систолічного і діастолічного АТ. Однак за даними добового моніторування АТ у пацієнтів із РАГ реєструвався значно більший рівень САТ протягом доби, дня та ночі, а також показник середнього ДАТ вночі (табл.). Дані ДМАТ свідчать, що серед пацієнтів з РАГ 2-й ступінь гіпертензії зафіксовано у 15 пацієнтів, 3-й ступінь - у 5 пацієнтів. У групі 3 ПРАГ розподіл пацієнтів за ступенем АГ був таким: 1-й ступінь - 6 пацієнтів, 2-й ступінь - 14 пацієнтів, 3-й ступінь - 4 пацієнти.Як видно з таблиці групи були зіставні за віком, IMT, офісним систолічним та діастолічним АТ.

Натомість, пацієнти з РАГ мали вищий рівень САТ за даними ДМАТ, ніж пацієнти групи порівняння. Середньоденний САТ 173,5 $\pm 2,9$ проти $164,6 \pm$ 2,4 мм рт.ст. $(\mathrm{p}=0,04)$ та середньонічний САТ 161,9 $\pm 3,4$ мм рт.ст. проти $148,6 \pm 4,2$ мм рт.ст. $(\mathrm{p}=0,02)$. Дані ДАТ за ДМАТ у порівнюваних групах достовірно не різнилися. Добові індекси за САТ і ДАТ були значно нижчими в групі пацієнтів із РАГ. Фізіологічний двофазний циркадний ритм АТ (“dipper”) у I групі спостерігали лише в 7 (40\%) пацієнтів, решта пацієнтів мали порушення добового ритму АТ: 3 недостатнім зниженням нічного АТ («non-dipper») - 8 (35\%) хворих; найбільш несприятливий у прогностичному відношенні тип порушення добового ритму, коли нічний AT значно вищий за денний AT, — «nigh-

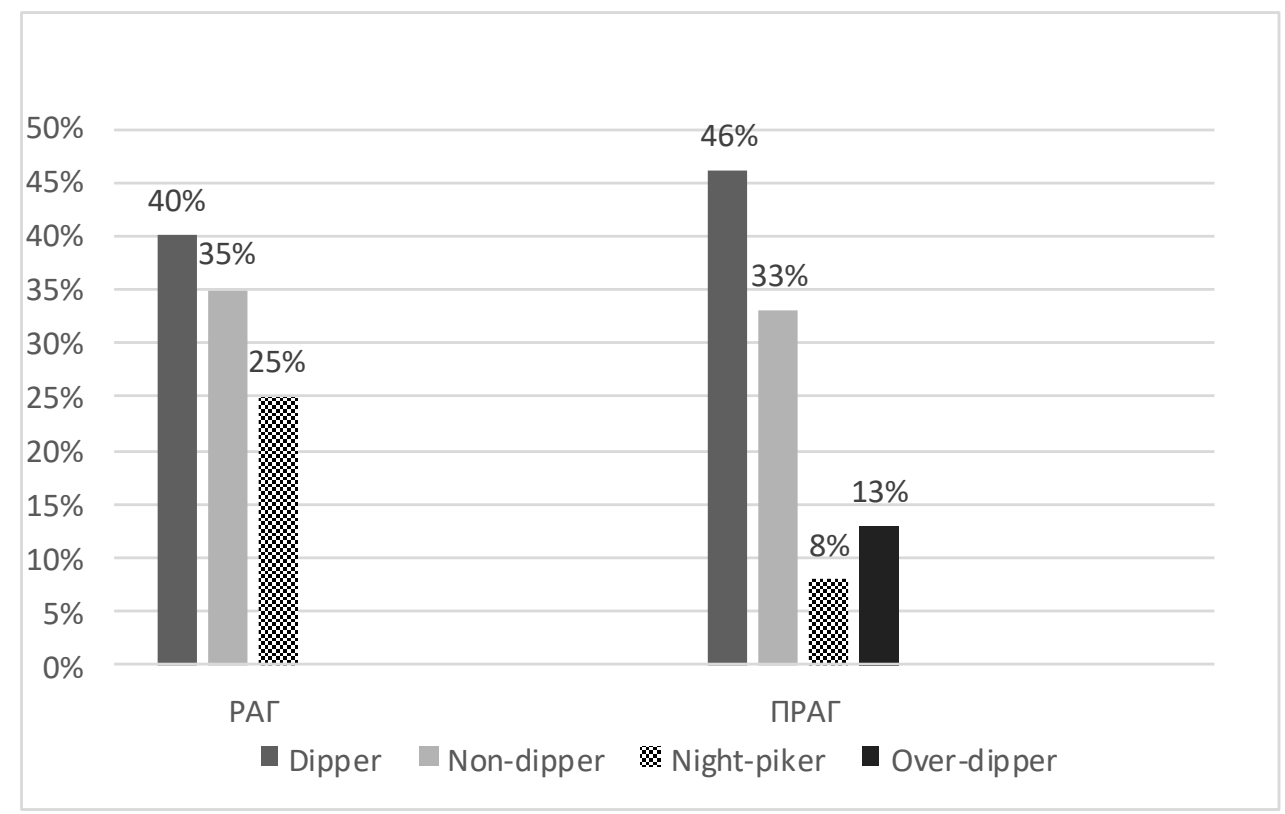

Рис. Розподіл типів циркадного ритму артеріального тиску у пацієнтів з резистентною артеріальною гіпертензією та у пацієнтів з псевдорезистентною артеріальною гіпертензією. 
piker» - у 5 пацієнтів (25\%). У II групі 11 (45,8\%) пацієнтів мали нормальний добовий профіль АТ, у 8 $(33,4 \%)$ пацієнтів виявлено його порушення за типом «non-dipper», лише у двох пацієнтів спостерігали тип «nigh-piker» (8,3\%), та в трьох пацієнтів (12,5\%) зафіксували надмірне зниження АТ у нічний період тип “over-dipper” (рис.). Порушення варіабельності АТ значно частіше виявляли в I групі (72,7\%), ніж у II групі - 43,0\% (p=0,04). Ранкові прирости САТ i ДАТ теж були достовірно вищими у хворих I групи ( $p=0,026$ i $p=0,001$ відповідно). Переважання добового ритму АТ за типом «non-dipper» у пацієнтів із РАГ підтверджується і даними літератури [7].

Gupta A. та співав. стверджують, що чим більший середній показник тиску за добу, за даними ДМАТ, тим вищий ризик розвитку РАГ [8]. За нашими даними, циркадний ритм АТ за типом «non-dipper» характеризувався значно вищими показниками САТ та ДАТ протягом доби у пацієнтів із РАГ порівняно із середньодобовими САТ і ДАТ у пацієнтів з профілем циркадного ритму АТ «non-dipper» у групі ПРАГ.

У багатьох дослідженнях показано, що підвищення тиску в нічний період та добовий ритм А за типом «non-dipper» $є$ найсильнішими факторами формування різного роду ускладнень при РАГ $[4,9]$. У зв'язку 3 чим необхідно уважно приділяти увагу саме ступеню нічного зниження АТ. Крім того, підвищення цих параметрів також асоціює і з АГ та розвитком серцево-судинних ускладнень [10]. За результатами нещодавно завершеного дослідження МАРЕС, що включало в себе велику когорту хворих на РАГ, встановлено, що середній рівень нічного АТ, визначений за даними ДМАТ, є незалежним фактором ризику серцево-судинних та цереброваскулярних подій, ніж АТ у денні години. Ці дані необхідно враховувати під час лікування пацієнтів із РАГ для зниження рівня захворюваності та смертності від серцево-судинних захворювань серед пацієнтів із РАГ [11].

\section{Висновки}

1. Пацієнти з резистентною артеріальною гіпертензією характеризуються більш високими показниками систолічного артеріального тиску за даними добового моніторування артеріального тиску в денний та нічний період, порівняно з пацієнтами з псевдорезистентною артеріальною гіпертензією.

2. Пацієнти з резистентною артеріальною гіпертензією мають частіші порушення циркадного ритму за типом «non-dipper», «night-piker», ніж у групі 3 псевдорезистентним перебігом артеріальної гіпертензії.

3. Ранковий приріст артеріального тиску, як систолічного артеріального тиску, так і діастолічного артеріального тиску, значно вищі в групі хворих на резистентну артеріальну гіпертензію, що є несприятливим прогностичним фактором для цієї категорії пацієнтів.

Перспективи подальших досліджень. Оскільки дані анамнезу свідчать, що пацієнти з резистентною артеріальною гіпертензією асоціюються з більшою тривалістю артеріальної гіпертензії, вищими цифрами артеріального тиску та частішим розвитком серцево-судинних ускладнень, слід удосконалювати ранню діагностику РАГ для якомога скорішого початку адекватної терапії, що є метою подальших досліджень, результати яких будуть викладені в наступних публікаціях.

Конфлікт інтересів відсутній.

Список літератури

1. Roberie DR, Elliott WJ. What is the prevalence of resistant hypertension in the United States? Curr Opin Cardiol. 2012; 27 (4): 386-91.

2. Giuseppe Mancia, Robert Fagard, Krzysztof Narkiewicz, Josep Redon, Alberto Zanchetti, Michael Böhm, Thierry Christiaens, Renata Cifkova, Guy De Backer. 2013 ESH/ESC Guidelines for the management of arterial hypertension: The Task Force for the management of arterial hypertension of the European Society of Hypertension (ESH) and of the European Society of Cardiology (ESC). European Heart Journal. 21 July 2013; 34 (28): 2159-219.

3. Коваленко ВМ, Корнацький ВМ. Проблеми здоров'я i тривалості життя в сучасних умовах. Київ. Друкарня "Гордон". 2016. 261 c.

4. Cardoso CR, Salles GF. Prognostic Importance of Ambulatory Blood Pressure Monitoring in Resistant Hypertension: Is It All that Matters? Curr Hypertens Rep. 2016; 18 (12): 85.

5. Pioli MR, Ritter AM, Modolo R. Un-sweetening the Heart: Possible pleiotropic effects of SGLT2 inhibitors on cardio and cerebrovascular alterations in resistant hypertensive subjects. Am J Hypertens. 2018; 31 (3): 274-80.

6. Mancia G, Verdecchia P. Clinical value of ambulatory blood pressure: evidence and limits. Circ Res. 2015; 116 (6): 103445.

7. Kansui Y, Matsumura K, Kida H, Sakata S, Ohtsubo T, Ibaraki A, Kitazono T. Clinical characteristics of resistant hypertension evaluated by ambulatory blood pressure monitoring. Clin Exp Hypertens. 2014; 36 (7): 454-8.

8. Gupta AK, Efthimia G Nasothimiou, Choon L Chang, Peter S Severet, et al. Baseline predictors of resistant hypertension in the Anglo-Scandinavian Cardiac Outcome Trial (ASCOT): a risk score to identify those at high-risk. J Hypertens. 2011; 29 (10): 2004-13.

9. Shafi S, Sarac E, Tran H. Ambulatory blood pressure monitoring in patients with chronic kidney disease and resistant hypertension. J Clin Hypertens (Greenwich). 2012;14 (9): 611-17.

10. Stavropoulos K, Imprialos KP. Sacubitril/valsartan instead of renin-angiotensin system inhibition alone: A step forward in resistant hypertension. 2018; 20 (1): 65-68.

11. Hermida RC, Diana E Ayala, María T Ríos, José R Fernández, Artemio Mojón, Michael H Smolensky. Around-the-clock ambulatory blood pressure monitoring is required to properly diagnose resistant hypertension and assess associated vascular risk. Curr Hypertens Rep. 2014; 16 (7): 445.

\section{References}

1. Roberie DR, Elliott WJ. What is the prevalence of resistant hypertension in the United States? Curr Opin Cardiol. 2012;27(4):386-91.

2. Mancia G, Fagard R, Narkiewicz K, Redon J, Zanchetti A, Böhm M, et al. 2013 ESH/ESC Guidelines for the management of arterial hypertension: The Task Force for the management of arterial hypertension of the European Society of Hypertension (ESH) and of the European 
Society of Cardiology (ESC). European Heart Journal. 2013;34(28):2159-219.

3. Kovalenko VM, Kornats'kyi VM. Problemy zdorov'ia i tryvalosti zhyttia $v$ suchasnykh umovakh [Problems of health and life expectancy in modern conditions]. Kyiv; "Hordon"; 2016. 261 p. (in Ukrainian).

4. Cardoso CR, Salles GF. Prognostic Importance of Ambulatory Blood Pressure Monitoring in Resistant Hypertension: Is It All that Matters? Curr Hypertens Rep. 2016;18(12):85.

5. Pioli MR, Ritter AM, Modolo R. Unsweetening the Heart: Possible pleiotropic effects of SGLT2 inhibitors on cardio and cerebrovascular alterations in resistant hypertensive subjects. Am J Hypertens. 2018;31(3):274-80.

6. Mancia G, Verdecchia P. Clinical value of ambulatory blood pressure: evidence and limits. Circ Res. 2015;116(6):1034-45.

7. Kansui Y, Matsumura K, Kida H, Sakata S, Ohtsubo T, Ibaraki A, et al. Clinical characteristics of resistant hypertension evaluated by ambulatory blood pressure monitoring. Clin Exp Hypertens. 2014;36(7):454-8.

8. Gupta AK, Nasothimiou EG, Chang CL, Sever PS, Dahlöf B, Poulter NR. Baseline predictors of resistant hypertension in the Anglo-Scandinavian Cardiac Outcome Trial (ASCOT): a risk score to identify those at high-risk. J Hypertens. 2011;29(10):2004-13.

9. Salman S, Erdal S, Huy T. Ambulatory Blood pressure monitoring in patients with chronic kidney disease and resistant hypertension. J Clin Hypertens (Greenwich). 2012;14(9):611-17.

10. Stavropoulos K, Imprialos KP, Doumas M. Sacubitril/ valsartan instead of renin-angiotensin system inhibition alone: A step forward in resistant hypertension. 2018;20(1):65-8.

11. Hermida RC, Ayala DE, Ríos MT, Fernández JR, Mojón A, Smolensky MH. Around-the-clock ambulatory blood pressure monitoring is required to properly diagnose resistant hypertension and assess associated vascular risk. Curr Hypertens Rep. 2014;16(7):445.

\section{Відомості про автора:}

Шеремет Марина Юріївна - аспірант відділу гіпертонічної хвороби ДУ ННЦ «Інституту кардіології імені академіка М.Д. Стражеска», вул. Народного Ополчення, 5, м. Київ, 02000, Україна

Сведения об авторе:

Шеремет Марина Юрьевна — аспирант отдела гипертонической болезни ГУ ННЦ «Институт кардиологии имени академика Н. Д. Стражеска», ул. Народного Ополчения, 5, г. Киев, 02000, Украина

Information about the author:

Sheremet Maryna Yuriyvna — post graduate student of the Department of Hypertension of the National Scientific Center "M. D. Strazhesko Institute of Cardiology", Narodnogo Opolcheniya St., 5, Kyiv, 02000, Ukraine

Надійила до редакції 26.06.2018

Рецензент - проф. Сидорчук Л.П. (C) М.Н. Неремет, 2018 